\title{
O RESGATE DO HUMANISMO NATURAL E AS SUAS CONTRIBUIÇÕES PARA O DESENVOLVIMENTO DOS PRESSUPOSTOS POLÍTICO- ECONÔMICOS DA CULTURA JURÍDICA OCIDENTAL
}

THE RESCUE OF NATURAL HUMANISM AND ITS CONTRIBUTIONS TO THE DEVELOPMENT OF POLITICAL AND ECONOMIC PREMISES OF WESTERN LEGAL CULTURE

II RISCATTO DELL'UMANESIMO NATURALE E I SUOI CONTRIBUTI ALLO SVILUPPO DEI PRESUPPOSTI POLITICO-ECONOMICI DELLA CULTURA GIURIDICA OCIDENTALE

\section{Rafael Padilha dos Santos ${ }^{1}$ \\ Maurizio Oliviero²}

\section{Liton Lanes Pilau Sobrinho ${ }^{3}$}

1 O autor é Mestre em Filosofia pela UFSC; tem especialização em processo civil pela UNIVALI; especialização em psicologia social pela Universidade Estatal de São Petersburgo, na Rússia. E Professor do curso de Direito da UNIVALI e está cursando o doutorado na UNIVALI com dupla titulação com a Università degli Studi di Perugia, na Itália, tendo realizado doutorado sanduíche na Università degli Studi di Perugia com bolsa CAPES mediante processo no 18034-12-8.

2 Embaixador Erasmus para a Itália. Doutor em Direito Público pela Università di Roma (Itália). É Professor Titular de Direito Público Comparado na Università degli Studi di Perugia (Itália). Professor Visiting na Columbia University - New York (EUA). Professor Visitante na Universidade do Vale do Itajaí - UNIVALI (Brasil); na Universidad de Alicante (Espanha); na Al-Quds University of Jerusalem e na Üniversite Eskesir (Turquia).

3 Doutor em Direito pela Universidade do Vale do Rio dos Sinos - UNISINOS (2008), Mestre em Direito pela Universidade de Santa Cruz do Sul - UNISC (2000). Possui graduação em Direito pela Universidade de Cruz Alta (1997). Professor dos cursos de Mestrado e Doutorado no Programa de Pós-Graduação Stricto Sensu em Ciência Jurídica da Universidade do 
Resumo: A passagem da Idade Média para a Idade Moderna conheceu como seu momento mais fecundo o Humanismo, que reabilitou os conceitos de civitas, a interpretação do ser humano como responsável pelas suas ações, a separação da congregatio fidelium e da congregatio hominum, a separação entre lei divina e lei humana, uma nova concepção de ciência política que considera a Igreja subordinada ao Estado, a consideração acerca da soberania popular. Tudo isso foi a expressão de uma humanidade natural reabilitada operada pelo humanismo italiano. Deste modo, este estudo tem por objetivo esclarecer as contribuições do humanismo italiano para a compreensão dos pressupostos políticos e econômicos formadores da cultura política, jurídica e econômica ocidental. As conquistas do humanismo estão amparadas em uma nova consideração sobre o ser humano, não entendendo mais o homem que se regenera por meio do batismo, mas do homem que é apenas humano e racional, ideia essa que depois avança à concepção de governo e economia, definindo um novo contexto de vida para a sociedade.

Palavras chave: Humanismo. Sociedade. Civitas. Homem natural.

Abstract: The most fertile time of the transition from the Middle Age to the Modern Age was the era of humanism, which restored the concepts of civitas, the interpretation of the human being as responsible for his actions, the separation of the congregatio fidelium and the congregatio hominum, the separation between divine law and human law, a new concept of political science that considers the church as subordinated to the State, and the consideration of popular sovereignty. All of this was the expression of a restored natural humanity operated by the Italian humanism. This study aims to clarify the contributions of Italian humanism to the understanding of political and economic premises that form the western political, legal and economic culture. The achievements of humanism are supported by a new consideration of the human being, no longer seeing man as regenerated by the baptism, but man who is only human and rational, an idea that later progressed to the concept of government and economy, defining a new context of life for society. 
Keywords: Humanism. Society. Civitas. Natural Man.

Riassunto: Il passaggio dal Medioevo all'età moderna ha vissuto nell'Umanesimo il suo momento più fertile, che ha riabilitato i concetti di civitas, l'interpretazione dell'essere umano come responsabile delle sue azioni, la separazione della congregatio fidelium e della congregatio hominum, la separazione tra legge divina e legge umana, una nuova concezione di scienza politica che considera la Chiesa come subordinata allo Stato, le considerazioni sulla sovranità popolare. Tutto questo è stato espressione di una umanità naturale riabilitata prodotta dall'umanesimo italiano. Pertanto, questo studio si propone di chiarire i contributi dell'umanesimo italiano per la comprensione dei presupposti politici ed economici fondanti della cultura politica, giuridica ed economica occidentale. Le conquiste dell'umanesimo sono supportate da una nuova considerazione circa l'essere umano, inteso non più come uomo che si rigenera nel battesimo, ma come uomo puramente umano e razionale, idea che avanza poi verso la concezione di governo e di economia che delinea un nuovo contesto di vita per la società.

Parole chiave: Umanesimo. Società. Civitas. Uomo naturale

\section{INTRODUÇÃO}

S conceitos de civitas, a reabilitação do ser humano como
responsável pelas suas ações, a separação da congregatio
fidelium e da congregatio hominum, a separação entre lei divina e lei humana, uma nova concepção de ciência política que considera o Estado separado da Igreja, foram a expressão de uma humanidade natural reabilitada operada pelo humanismo italiano.

É do humanismo italiano o mérito de estabelecer o início de um processo de secularização da civilização europeia, mediante a redescoberta do homem natural que age racionalmente em razão do seu bem viver. É verdade que ainda

Vale do Itajaí. Professor da Universidade de Passo Fundo. 
nesta época, no modo da filosofia, Deus não havia se retirado do contato cultural com os homens, mas isso porque a revolução ocorre em um processo gradual, não em um corte repentino.

Assim, para Garin4, o humanismo italiano não consistiria em uma filosofia ímpia ou herética, já que respeitosa da fé religiosa, ainda que os humanistas renunciem aos discursos de Deus para, por meio do intelecto, pesquisar o modo das cidades humanas, dos costumes, dos ritos humanos ou, no âmbito científico, identificar a natureza das doenças ou a estrutura dos viventes.

Pois bem, para Garin a essência do humanismo é encontrada não na cultura dos clássicos do passado, mas na atitude assumida diante de tal cultura, atitude esta que apresenta uma consciência histórica bem delimitada:

Proprio l'atteggiamento assunto di fronte alla cultura del passato, al passato, definisce chiaramente l'essenza dell'umanesimo. E la peculiarità di tale atteggiamento non va collocata in un singolare moto d'ammirazione o d'affetto, né in una conoscenza più larga, ma in una ben definita coscienza storica. ${ }^{5}$

Para Garin, tal consciência histórica se expressa nos humanistas por terem compreendido os clássicos gregos e romanos no contexto da sua realidade histórica, constituindo obras válidas que abrem o conhecimento da própria vida humana. Por exemplo, os humanistas devolveram Virgílio e Aristóteles - que eram lidos na Idade Média - ao seu tempo e ao seu mundo, o que implica uma descoberta do mundo antigo que, para os humanistas, implicava uma unidade com a descoberta do próprio ser humano. Como sintetiza Garin, descobrir o antigo: "Significò tempo e memoria, e senso della creazione umana e dell'opera terrana e della responsabilità." 6

Neste contexto, o objeto deste estudo é esclarecer as contribuições do humanismo italiano para a compreensão dos pressupostos políticos e econômicos formadores da cultura política, jurídica e econômica ocidental.

4 GARIN, Eugenio. L'umanesimo italiano: filosofia e vita civile nel Rinascimento. Roma: Laterza, 1994. p. 10-11.

5 GARIN, Eugenio. L'umanesimo italiano: filosofia e vita civile nel Rinascimento. 1994. p. 21.

6 GARIN, Eugenio. L'umanesimo italiano: filosofia e vita civile nel Rinascimento. 1994. p. 22. 


\section{A SECULARIZAÇÃO DA CIVILIZAÇÃO EUROPEIA}

Nos escritos, por exemplo, de Petrarca, Coluccio Salutati, Leonardo Bruni, Marsílio de Pádua, há páginas políticas em que é exposta a harmonia nas relações entre homens livres sob uma constituição concebida por esses próprios homens, além dos pressupostos para entender-se o homem natural e racional e para colher a racionalidade econômica na história, textos que precedem e cujo valor é equivalente ou ainda superior àqueles de Grocio, Locke, Montesquieu, Smith7 .

São os autores do humanismo que consentem visualizar claramente a passagem da cosmologia eclesiástica para uma história escrita em consideração à ação racional do homem natural, ou seja, a uma história criada pelo homo faber suae fortunae. O homem afirma a si mesmo e emprega sua racionalidade para de modo responsável alcançar o prazer e evitar o sofrimento. Os humanistas resgatam o homem natural, concentram-se sobre sua substância natural, sua humanitas. Por isso, afirma Nuccio:

Per la prima volta e con la filosofia umanistica italiana l'individuo umano, con i suoi interessi, le sue iniziative, il suo desiderio di felicità, soprattutto con la sua ragione, condizione per l'uso fortunato di tutte le altre sue facoltà, appariva il fondamento su cui costruire una società stabile. ${ }^{8}$

Para tanto, foi preciso uma passagem que o pensamento advindo da literatura eclesiástica e cristocêntrica não admitiria facilmente, qual seja: o esforço para redescobrir o homem natural, um homem nem fiel, nem cristão, mas somente homem, o que foi fruto do pensamento italiano, como afirma Ullmann: "Il suolo italiano era destinato in un senso del tutto specifico a giocare un ruolo vitale nel contesto dell'umanesimo.. ${ }^{\prime 9} \mathrm{O}$ renascimento do homem natural, do qual deriva a racionalidade econômica e política moderna, decorre da passagem dos studia divinitatis para os studia humanitatis, do fidelis ao civis.

$7 \quad$ NUCCIO, Oscar. Diritto naturale e razionalità economica: studi sulle origini medievali dello "spirito capitalistico". Roma: Edizioni dell'Ateneo, 1989. p. 15.

8 NUCCIO, Oscar. Diritto naturale e razionalità economica: studi sulle origini medievali dello "spirito capitalistico". 1989. p. 15.

9 ULLMANN, Walter. Radici del Rinascimento. Roma: Laterza, 1980. p. 18. 
Com os studia divinitatis, o homem era refutado, conforme corrente de entendimento encabeçada por Santo Agostinho, que entendia, contrariando os filósofos pagãos, que o bem supremo não poderia ser encontrado nesta vida, na virtude humana, ou seja, que a felicidade poderia ser vivida somente em uma vida futura, em uma promessa indemonstrável de um paraíso. Pensamento este seguido por Pier Damiani (1007-1072) e Anselmo de Aosta (1033/1034-1109), conhecido como Doutor Magnífico, que defendia uma retidão de vontade para que o sujeito viesse a gozar futuramente uma felicidade decorrente da união com Deus: "una felicità assolutamente ingannevole, mentre il cristiano comprendeva che il suo fine, il vero fine, era solo in una vita futura."

Com Tomás de Aquino, no século XIII, é realizada uma passagem essencial à humanitas por seguir uma explicação que dá lugar ao racionalismo natural: a natureza humana é situada como parte integrante da ordem divina e funcionando sob princípios próprios, do qual o principal é o instinctus naturae, o qual leva à agregação social e gera harmonia. Dentro da teologia, é possível admitir que a razão humana pode levar o homem ao bem viver. Como explica Nuccio: "Prendendo l'istinto naturale il suo posto nelle cose umane, I'humanitas dell'uomo veniva a ricevere un'attenzione più profonda."10

\section{SÃO TOMÁS DE AQUINO E O HUMANISMO}

Werner Jaeger ${ }^{11}$, em seu livro Umanesimo e teologia, esforça-se por expor sua ideia sobre a posição do humanismo em relação à tradição medieval e ao problema da teologia partindo do aspecto humanista da visão teocêntrica do mundo de São Tomás de Aquino. A visão teocêntrica do mundo é assim conceituada por Jaeger:

Per visione teocentrica del mundo intendo quella visione del mondo comune a tutti i pensatori medievali e a ogni fedele cristiano, secondo la quale ogni elemento della vita umana e della realtà in generale veniva riferito a Dio come norma assoluta di perfezione, come il più

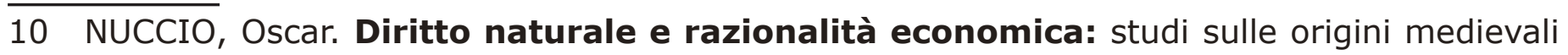
dello "spirito capitalistico". 1989. p. 17.

11 JAEGER, Werner. Umanesimo e teologia. Milano: Corsa dei Servi, 1958. p. 14. 
alto principio dell'essere. ${ }^{12}$

Já a teologia é assim definida: "Chiamiamo teologia il sistema teoretico in cui questa visione si esprimeva."13 A teologia, no entanto, não está ligada estritamente à teologia cristã, uma vez que a palavra "teologia" tem por origem a cultura clássica grega, ou seja, não é uma terminologia nem originariamente cristã nem medieval. A teologia cristã é normalmente relacionada à teologia revelada ou à teologia sobrenatural, diferentemente da teologia natural ou racional, relacionada à concepção dos antigos filósofos gregos, diferenciação essa considerada pelo próprio Tomás de Aquino14. Partindo dos antigos filósofos, elucida Jaeger: "Il concetto di teologia originariamente indicava ogni forma di accostamente razionale al problema di Dio." ${ }^{15}$

A teologia de São Tomás de Aquino busca um resultado racional ao problema de Deus, favorecido pela descoberta, em sua época, das principais obras de Aristóteles, que até então eram desconhecidas pelas nações ocidentais do mundo medieval. Cabe a menção, partindo da explicação de Jourdain ${ }^{16}$, que o século XIII foi precedido por um impulso que a filosofia conheceu a partir do século $\mathrm{XI}$, primeiramente a partir da oposição entre as correntes entre nominalistas e realistas, depois, com uma nova postura, que além da filosofia racional (philosophie rationnelle) envolvia também os diversos ramos da filosofia: as ciências naturais, a matemática, a metafísica, tornando-se tudo objeto de estudos comuns, de modo que, no final do século XIII, os filósofos gregos e romanos ganharam corpo, importância e reconhecimento, sendo que as escolas divulgavam seus nomes e exigiam o seu estudo. Além disso, também eram conhecidos e ganharam grande reputação os filósofos árabes, nos nomes, dentre outros, de Avicenas, Averroe, Aven-Pace ${ }^{17}$. Ou seja, a cultura não estava apagada, havia atividade, a língua

12 JAEGER, Werner. Umanesimo e teologia. 1958. p. 15.

13 JAEGER, Werner. Umanesimo e teologia. 1958. p. 15.

14 AQUINO, Tomás de. Suma contra os gentios. 1 v. Tradução: D. Odilão Moura. Porto Alegre: Sulina, 1990. p. 22.

15 JAEGER, Werner. Umanesimo e teologia. 1958. p. 15.

16 JOURDAIN, Amable Louis Marie Michel Bréchillet; JOURDAIN, Charles. Recherches critiques sur l'age et I'origine des traductions latines d'Aristote et sur des commentaires grecs ou arabes employés par les docteurs scolastiques. Paris: Joubert, 1819. p. 1-3.

17 Sobre o argumento, consultar também: GILSON, Étienne. Études de philosophie médiévale. Strasbourg: Faculté des Lettres, 1921. GILSON, Étienne. La philosophie au 
latina é valorizada e empregada e, como explica Jourdain: "Aristote joua le plus grand rôle dans cette circonstance." ${ }^{\prime 18}$

O desafio na Idade Média era respeitar as fontes da cultura antiga de profunda maturidade intelectual descoberta nos textos gregos, sem desrespeitar os dogmas e a fé da religião cristã. A assimilação seria impossível, partindo-se de uma frase como: "credo quia absurdum" (creio porque é absurdo) inspirada em Tertuliano (155-220) a partir de sua obra De carne Christi, quando sustenta que a crucificação e a morte de Cristo podem ser acreditadas porque inconcebíveis e a ressurreição é certa porque impossível, expressando um credo cristão fideísta, em que os dogmas são sustentados com tanto mais afinco quanto mais se contrapõem à razão. Uma solução mais coerente é "credo ut intelligam" (creio para entender), introduzida por Santo Agostinho e repetida por Santo Anselmo de Cantuária (1033-1109).

Por meio de Aristóteles, São Tomás explica em suas lições aos seus alunos, como afirma Jaeger ${ }^{19}$, as etapas, em escala ascendente, dos graus do conhecimento humano, até tocar ao princípio supremo do mundo, isto é, a forma sem matéria que é ato puro e move todo o mundo e as criaturas, movendo sem ser movido por meio da sua própria perfeição da mesma forma que o amado move o amante. São Tomás volta-se para a metafísica grega, propondo um novo racionalismo teológico que, no século XIII, representou um renascimento do espírito clássico. Por isso, como ensina Jaeger ${ }^{20}$, em tal perspectiva São Tomás não pode ser oposto aos humanistas do Renascimento, mas a uma modalidade de piedade cristã insensível à influência da filosofia grega.

Aristóteles inicia sua obra Metafísica afirmando: "Todos os homens têm, por natureza, desejo de conhecer"21. Os seres humanos possuem um natural desejo pelo saber e, deste princípio, Aristóteles deduz o conceito da ciência suprema ou teologia natural. Partindo de Aristóteles, os tomistas ensinam que, sendo natural tal desejo pelo saber, significa que tal desejo teria sido dotado por Deus moyen age. Paris: Payot, 1922.

18 JOURDAIN, Amable Louis Marie Michel Bréchillet; JOURDAIN, Charles. Recherches critiques sur l'age et I'origine des traductions latines d'Aristote et sur des commentaires grecs ou arabes employés par les docteurs scolastiques. 1819. p. 3.

19 JAEGER, Werner. Umanesimo e teologia. 1958. p. 18.

20 JAEGER, Werner. Umanesimo e teologia. 1958. p. 20.

21 ARISTÓTELES. Metafísica. São Paulo: Abril Cultural, 1984. p. 11. 
no homem. Deste modo, tal potencialidade inata, comprovada por tal desejo pelo saber, sendo direcionada por exercícios metódicos do intelecto, conduz ao conhecimento de Deus como o grau mais elevado de consciência humana, uma alta realidade e perfeição. Deste modo, Deus criou a natureza humana com uma tensão que o impele ao saber verdadeiro, devendo ser o conhecimento verdadeiro a guiar o homem até Deus.

Assim, o homem não deve descuidar de uma faculdade que lhe foi concedida para ser desenvolvida mediante uma formação que lhe leve à autêntica realização de seu destino. O desejo humano não deve dilatar-se de qualquer modo ou em qualquer direção, o ser humano precisa de uma formação de base para encontrar o bom caminhar, o que é reconhecido pelo próprio Dante: "lo buono camminatore giugne a termine e a posa; lo erroneo mai non l'aggiugne, ma con molta fatica del suo animo sempre con li occhi gulosi si mira innanzi." ${ }^{22}$

São Tomás de Aquino ${ }^{23}$ explica que o homem é dotado do desejo natural pelo saber pelos seguintes motivos: 1- o saber constitui a perfeição do homem, e cada coisa deseja a própria perfeição, de modo que o homem deve relacionar o conhecimento atual com a sua potencialidade cognitiva; 2- já que todo ser tem a propensão natural de agir no modo de sua identidade, sendo o modo próprio do homem a atividade intelectual, é esta quem o distingue dos demais animais e que deve ser exercitada; 3- todo ser deseja ser reunido ao seu princípio, à substância que revela o intelecto na sua perfeição. Este último argumento também foi utilizado por Dante Alighieri na sua obra Convivio, ao afirmar: "lo sommo desiderio di ciascuna cosa, e prima de la natura dato, è lo ritornare a lo suo principio." 24 São esses os motivos pelos quais a satisfação de tal desejo de saber são essenciais para a felicidade humana.

Assim, a natureza humana é central na teologia de São Tomás de Aquino e a discussão é resolvida no âmbito da filosofia, em que trabalha não apenas a metafísica, mas também a ética aristotélica - uma vez que a felicidade para

22 DANTE, Alighieri. Convivio. In: DANTE Alighieri: tutte le opere. 8. ed. Roma: Grandi Tascabili Economici, 2013. p. 984.

23 AQUINO, Tomás de. Commento alla metafisica di Aristotele. 1 v. Bologna: PDUL, 2004. p. 51-53.

24 DANTE, Alighieri. Convivio. In: DANTE Alighieri: tutte le opere. 2013. p. 983. 
Aristóteles está ligada a uma atividade conforme a faculdade intelectual do homem. A concepção de "natureza" para os gregos implicava um modo perfeitamente objetivo de a mente humana relacionar-se à realidade, sendo tal pressuposto essencial para Tomás de Aquino, elaborando um sistema filosófico que abre uma nova abordagem para aquilatar a racionalidade da natureza humana e do mundo.

Deste modo, São Tomás de Aquino desenvolve uma visão teocêntrica que revela diversas interseções ao humanismo futuro pelos seguintes motivos: a) parte da mesma forma que o humanismo, de uma concepção de natureza humana; b) para formular tal concepção de natureza humana considera a cultura helênica resgate do clássico comum ao humanismo; c) realiza uma abordagem racional em relação à realidade, inclusive à realidade de Deus, herança dos gregos, posto que a cultura grega assume como suporte a natureza humana e a razão ${ }^{25}$.

\section{A PASSAGEM AO HOMEM NATURAL NO HUMANISMO CIVIL: UMA NOVA ORGANIZAÇÃO POLÍTICA E ECONÔMICA}

Progressivamente, com o advento do humanismo, avança-se à ideia de que o governo do que é humano cabe ao ser humano, que o homem possui uma força intelectual capaz de reger sua própria existência e, neste caso, prover a própria felicidade.

Essa transição torna-se bastante visível com Marsílio de Pádua (1275/801342/43) ${ }^{26}$, em sua obra Defensor Pacis ${ }^{27}$, marcando uma reelaboração da compreensão medieval sobre o homem. Distinguia uma dupla felicidade: a felicidade terrena, que acontece em conformidade à racionalidade humana; e a felicidade celeste, que não é demonstrável pela filosofia. Seu racionalismo desemboca na sustentação de um humanismo político, assumindo que a constituição dos principados é decorrente da mente humana.

Portanto, não se trata do homem que se regenera por meio do batismo, mas do homem que é apenas humano e racional, ponto de partida a partir 25 JAEGER, Werner. Umanesimo e teologia. 1958. p. 25-26.

26 Tal visão é compartilhada por NUCCIO, Oscar. Diritto naturale e razionalità economica: studi sulle origini medievali dello "spirito capitalistico". 1989. p. 18-19.

27 MARÍSILIO DE PÁDUA. O defensor da paz. Petrópolis: Vozes, 1997. 
do qual extrai as consequências do seu pensamento. No Defensor pacis temse uma teoria do Estado na medida em que Marsilio de Pádua subordina a organização eclesiástica ao Estado - assim como o direito romano situava o jus sacrum no jus publicum ${ }^{28}$.

Marsílio de Pádua escreve essa obra sob direta influência da Política de Aristóteles. O pensamento de Aristóteles consente uma importante passagem para o resgate do homem natural, isso porque para Aristóteles o homem é concebido como um ser sociável, um animal político (zóon poliktikon), isto é, é da natureza humana ser gregário, ter uma vida civil, ou seja, o homem possui impresso em sua natureza a tendência em unir-se para viver no Estado e, realizando tal tendência, o homem realiza o seu próprio bem. Nas palavras de Aristóteles: "Fica evidente, pois, que a Cidade é uma criação da natureza, e que o homem, por natureza, é um animal político [isto é, destinado a viver em sociedade] [...]"29.

Portanto, tanto o homem quanto o Estado são criações naturais. O Estado, apesar de ser natural, não se origina sozinho, pois depende da ação deliberada e voluntária dos homens. Aristóteles assim revela a política como ciência prática, já que, para ser cidadão, é preciso tornar-se cidadão pela educação.

Essas ideias aristotélicas alcançaram os autores do século XIII, que interiorizaram a afirmação do homem como "animal político", capaz de uma organização diferente e muito mais elevada que outras espécies (como abelhas, formigas, etc.) e, além disso, a concepção de que o homem, por virtude de sua própria natureza, assume um papel central na realização de seu modelo de organização. É diferente de partir da ideia de Paulo e da doutrina cristã do homo animalis em que a criatura animal teria que renascer por meio do batismo como um "homem novo", pois agora o renascimento é do próprio homem natural na cidade terrena. Nas palavras de Ullmann: "L'uomo naturale, restaurato nella sua piena statura entro I' ordine secolare-mondano, si impose all'attenzione che gli era dovuta nella sua qualità di uomo in carne ed ossa." ${ }^{30}$

28 AVONDO, Edoardo Ruffini. Il Defensor pacis di Marsilio da Padova. In: Rivista storica italiana. Messina: Giuseppe Principato, 1924. p. 126.

29 ARISTÓTELES. Política. 5. ed. São Paulo: Martin Claret, 2001. p. 56.

30 ULLMANN, Walter. Radici del Rinascimento. 1980. p. 125. 
Assim, a razão foi emancipada da fé, voltada à organização e vida humana, aplicada na administração da sociedade. Essa recuperação do homem natural levou à consideração sobre o ser próprio do humano, a sua humanitas, o seu íntimo ser como expressão da substância própria do homem natural.

Passa-se assim ao estudo da humanitas natural do homem, diferentemente do que se fazia precedentemente, quando o interesse era pelo homem batizado, despojado de sua naturalidade. A concepção medieval do renascimento pelo batismo, do homem cristão, conferia uma fisionomia eclesiástica à sociedade, ao governo, ao direito, à soberania. Os efeitos do renascimento batesimal eram notáveis na vida pública, na ordem social, campo este em que o homem natural deveria exercer maior influência, o que foi realizado sob a base aristotélica para reformar o próprio direito, pois era o direito canônico quem encarnava na prática da vida social e do governo a ideia de renascimento batesimal. A ordem política sob concepção aristotélica introduz uma nova forma mental que concorreu com a ideologia eclesiástica, causando profundos efeitos políticos ${ }^{31}$.

As manifestações seculares ocorreram nos campos da vida pública, em que se resgata o interesse pela humanidade dos cidadãos sem dependência a questões religiosas ou sobrenaturais. Como explica Ullmann: "L'umanesimo iniziò il suo cammino trionfale come uma parte della indagine condotta sulla figura del citadino rinato che era membro integrante dello Stato naturale."32 Opera-se assim o renascimento da humanidade tendo em vista o cidadão e o Estado, focalizando no estudo da humanitas.

A concepção do homem natural passa a se ligar ao Estado, constituído por cidadãos, e a concepção sobrenatural fica restrita à Igreja, com seus fiéis, separando-se assim a jurisdição estatal e mundana da jurisdição eclesiástica. Considera-se apenas o homem gerado naturalmente, o Estado (natural) e a Igreja (sobrenatural).

É preciso ressalvar que, para os primeiros humanistas, o cidadão e o seu Estado, bem como o fiel e a sua Igreja, ainda que independentes - cada qual

32 ULLMANN, Walter. Radici del Rinascimento. 1980. p. 129. 
com premissas e fins diferentes-, eram suscetíveis de integração. Isso porque ainda era válida a ideia de São Tomás de Aquino de que Deus é o summus regens, o autor da natureza, ou seja, os humanistas ainda consideravam em suas obras a síntese do tomismo que integra elementos aristotélico-naturísticos e cristãosobrenaturais. Porém, tal ideia não justificava qualquer dependência do Estado à Igreja, entre os humanistas sequer tinha necessidade da Igreja sobrenatural.

Assemelha-se à concepção de São Tomás de Aquino ao falar do duplex ordo in rebus, cada entidade atua sob princípios diferentes: o Estado apresenta um governo ascendente e deveria adaptar-se às contingências, às orientações culturais diversas e diferentes organizações constitucionais e políticas que variam no tempo e no espaço - inclusive por força de questões climáticas ou físicas -, além de haver a possibilidade da decadência estatal; já a Igreja se orienta por outros princípios, tem um governo descendente, é instituída sem caráter variável, sua doutrina é imutável e deve simplesmente ser aplicada e seguida, prometendo a eternidade. O Estado baseia-se sob um instinto natural de socialização humana, enquanto a base da Igreja está na promessa divina ${ }^{33}$.

Deste modo, o direito é uma criação humana que utiliza a razão e a experiência para ser formulado. Para os humanistas, a lei não tem por necessidade a fé religiosa, mas o consenso alcançado racionalmente pelo debate humano. Porém, esse debate exigia exames metódicos sob argumentos racionais, um empenho pela política coligado a condições humanas da sociedade, entendendo-se a política como algo intramundano. Entra-se aqui numa nova categoria, denominada por Aristóteles de politeuein, traduzido por "politizar" ou "fazer política". Cícero34, por exemplo, não encontrou um correspondente grego a politikos, de modo que em seus escritos em latim, e os melhores manuscritos de suas obras, conservam sua forma grega, sem sua tradução ou transliteração ao latim.

Os cidadãos deveriam gerir as tarefas públicas no Estado, compondo-se assim uma tríade entre Estado, cidadão e política, tendo como ponto em comum a humanidade natural. O humanismo irá emergir junto com a concepção da 33 ULLMANN, Walter. Radici del Rinascimento. 1980. p. 132.

34 Como suas Epistolae ad familiares, 8.1.5 e Epistolae ad Atticum, 9.4, cf. ULLMANN, Walter.

Radici del Rinascimento. p. 134. 
ciência política de que o cidadão e o Estado são como órgãos da humanidade. ${ }^{35}$ Historicamente, o humanismo emergiu sob influência da ciência política.

Cabe frisar que a nova ciência política teve sua estrada aberta por Tomás de Aquino ${ }^{36}$, o qual tinha consciência, a partir do seu comentário à obra Ética a Nicômaco, ser ela uma scientia principalissima, uma ciência arquitetônica - já que determina o que as demais ciências devem fazer - , a mais importante das pesquisas intelectuais, porque ajudava a construir a sociedade humana, com a seguinte observação: "Ha de saberse que disse Aristóteles que la política es principal no absolutamente, sino en el género de las ciencias activas que versan sobre los assuntos humanos." ${ }^{37}$ Assim, distingue-se a ciência política da ciência divina.

Já Tomás de Aquino concebe que há de um lado a Igreja como congregatio fidelium, ou seja, uma comunidade de crentes fundada na fé, sendo que para tornarse seu membro é preciso da fé e o renascimento pelo batismo ${ }^{38 ;}$, e, de outro lado, a congregatio hominum, a comunidade política (congregatio politica), entendendo Tomás de Aquino que o governo de um só é o melhor governo ${ }^{39}$, e que a política não é consequência do pecado, como fazia Santo Agostinho, mas admitia o domínio político, assim definido: "referida a cualquier modo de tener a alguien sometido; y en este sentido domina quien tiene el gobierno o dirección de personas libres."40

Já Marsílio de Pádua, em sua obra Defensor Pacis, faz o povo base do Estado e da Igreja, constituindo no Estado a universitas civium e, na Igreja a universitas fidelium. Concebe a Igreja como subordinada ao Estado, e o Estado e a Igreja como submetidos ao povo, que é entendido como humanus legislator, situando a soberania popular como fundamento de todo o edifício político e social ${ }^{41}$.

35 ULLMANN, Walter. Radici del Rinascimento. Roma: Laterza, 1980. p. 134-135.

36 AQUINO, Tomás de. Comentario a la Ética a Nicómaco de Aristóteles. 3. ed. Pamplona: Ediciones Universidad de Navarra, 2010. p. 68.

37 AQUINO, Tomás de. Comentario a la Ética a Nicómaco de Aristóteles. 3. ed. Pamplona: Ediciones Universidad de Navarra, 2010. p. 69-70.

38 RAMOS, Alejandro. La ciudad de Dios en Santo Tomás de Aquino. Mar del Plata, Universidad FASTA, 2008.

39 AQUINO, Tomás de. Do reino ou do governo dos príncipes ao rei de Chipre. In: Escritos políticos de Santo Tomás de Aquino. Tradução de Francisco Benjamin de Souza Neto. Petrópolis: Vozes, 1995.

40 AQUINO, Santo Tomás de. Suma de teología. Parte I. 4. ed. Madrid: Biblioteca de autores cristianos. 2001. Parte I, Cuestión 96, art. 4. p. 853.

41 LABANCA, Baldassare. Marsilio da Padova: riformatore politico e religioso del secolo XIV. Padova: Fratelli Salmin, 1882. p. 126. 
Além de Marsílio de Pádua, com Leonardo Bruni constata-se a menção ao governo popular praticado em Florença, a exemplo do que ocorreu com a guerra de Lucca, que ele pessoalmente não era favorável, mas após deliberação e decisão do povo, aceitou-a e defendeu-a. Inclusive, Bruni escreveu uma obra em defesa da decisão do povo de Florença, que decidiu pela guerra por sentir-se ameaçado pelo comportamento de Paolo Guinigi, senhor de Lucca, aliado do duque de Milão Filippo Maria Visconti, que era inimigo histórico de Florença ${ }^{42}$.

O humanismo teve sua expressão inicial em relação ao renascimento do cidadão entendido como membro integrante da ideia do Estado, e para tal ideia concorreu decididamente Marsílio de Pádua, ao tratar do homem que com autonomia coloca a lei para orientar sua conduta guiado unicamente por sua razão natural.

Marsílio de Pádua assim define a lei: "è un precetto coattivo concernente gli atti umani che debbono essere fatti oppure omessi, sotto uma pena da infliggere a chi la trasgredisce."43 Distingue em seguida a lei humana da lei divina, já que a lei divina não envolveria deliberação humana, além de colocar um fim a ser alcançado na vida futura e uma pena aos transgressores que seria infligida em tal vida futura. Já a lei humana é um preceito coativo que deriva da vontade ou deliberação humana, com uma finalidade a ser realizada nesta vida e sob uma pena que pode ser cominada apenas nesta vida. A causa eficiente da lei humana não é Deus, mas "la mente umana o la sua scelta o volontà;" ${ }^{44}$

O humanismo civil italiano reconhece dois mundos conceitualmente diferentes, o da fé e o da razão. Assim, é possível dar uma base de legitimidade diferente daquela proposta pela Igreja em relação a condutas humanas que eram consideradas como ratione peccati, muitas delas relacionadas à economia. Isso porque a Igreja tinha uma normativa canônica severa antieconômica, a ponto de obstacularizar a atividade econômica e a circulação de riquezas. Há muitas condutas prescritas pela lei divina, mas não prescritas pela lei humana, como

42 BRUNI, Leonardo. Difesa contro i riprensori del popolo di Firenze nella impresa di Lucca. Leonardo Bruni: opere letterarie e politiche. A cura di Paolo Viti. Classici latini. Novara: UTET, 2013.

43 MARSILIO DA PADOVA. Il difensore minore. Napoli: Guida, 1975. p. 159.

44 MARSILIO DA PADOVA. Il difensore minore. 1975. p. 178. 
a usura - que é vetada pela lei divina -, em relação às que Marsílio afirma não encontrar contraste entre ambas as leis, assim como não é contrastante admitir: "che Pietro corra e Giacomo non corra;"45

Historicamente, essa já era uma aspiração existente na prática econômica e civil das comunas italianas, e o humanismo italiano fornece uma base para a compreensão da autossuficiência do indivíduo e para o renascimento do homem, seja ou não cristão. Como afirma De Roover: "Il capitalismo moderno, basato sulla proprietà privata, ha le sue radici nell'Italia del Meio Evo e del Rinascimento."46

A partir do século XIV, apresenta-se uma definição de bem como resultado da atividade do homem, que pela sua vita activa é capaz de realizar o bem viver, o homo faber artífice do quanto é útil à humanidade para sua civilidade. Leonardo Bruni é um humanista italiano que exalta o sentido e o valor da civitas, local em que o homem constrói o verdadeiro bem, uma cidade que não é feita de muros, mas de cidadãos ativos e de riqueza. Se a riqueza é necessária, ainda mais necessários são aqueles que produzem a riqueza.

Bruni, em muitos de seus escritos, exalta a cidade de Florença, como é a maior expressão o seu escrito Laudatio florentine urbis, em que é qualificado o esforço de descrever tal cidade não apenas como mirabilia urbis, mas que coloca no centro da reflexão a capacidade humana como artífice dessa organização civil, uma comunidade de seres humanos (congregatio hominum). Afirma Bruni:

E infatti, come gli stessi cittadini per un certo loro naturale ingegno, per prudenza, per elevatezza e magnificenza, moltissimo sopravanzano tutti gli altri uomini, così anche questa città, tanto accortamente situata, supera tutte le altre in splendore, in ornamento ed eleganza. ${ }^{47}$

Já na obra De militia, Bruni esclarece o significado de civitas, ao afirmar: "La città, infatti, è promotrice e autrice di tutta la vita e di tutti i compiti degli uomini." A cidade não é um agregado de edifícios, mas possui uma base humana, por isso, Leonardo Bruni não utiliza a palavra ubs, mas civitas, para dar a ideia da 45 MARSILIO DA PADOVA. Il difensore minore. 1975. p. 182.

46 DE ROOVER, Raymond. Il banco Medici: dalle origini al declino. Firenze: La Nuova Italia Editrice, 1970. p. 1.

47 BRUNI, Leonardo. Elogio della città di Firenze. Leonardo Bruni: opere letterarie e politiche. A cura di Paolo Viti. Classici latini. Novara: UTET, 2013. p. 507. 
participação das pessoas na vida comum. É na civitas que os cidadãos têm seus cargos distribuídos, suas necessidades saciadas, recebem a proteção, ou seja, uma união de muitos que provê as necessidades dos indivíduos. Para ser civitas, a cidade deve alcançar um desenvolvimento tal que seja autossuficiente, capaz de sustentar suas necessidades perante as exigências da vida ${ }^{48}$.

Leonardo Bruni, estudando os antigos filósofos, como Epicuro, Aristóteles, Teofrasto, os peripatéticos e os estoicos, indica como finalidade do homem o bem supremo, não mais entendido de modo escolástico como bem transcendental, mas sim aristotelicamente como felicidade do homem empírico, mediante um ethos direcionado ao bem viver, consagrando-o na praxis. E a virtude não deve ser vivida de modo isolado, mas em uma vida inserida na sociedade civil.

Bruni admite que algumas virtudes ligam-se mais à vida contemplativa, como a sapiência, a ciência e a inteligência, sendo esta uma vida mais elevada e rara; outras à vida ativa, como a prudência, que é uma vida mais eficaz no interesse comum. De todo modo, a prospectiva do homem deve ser a felicidade, e a felicidade é alcançada não pelos vícios, mas pela virtude, pelo bem viver e o bem agir, nas palavras de Bruni: "Se dunque vogliamo essere felici, impegnamoci ad essere perbene e pratichiamo le virtù." ${ }^{49}$

Assim, os humanistas italianos realizaram uma concepção diferenciada da natureza humana, conciliando a parte espiritual com a parte corporal e material.

\section{CONSIDERAÇÕES FINAIS}

Antes do advento do humanismo, a Itália vive um período em que, por meio do papa Inocêncio III (1161-1216), papa da Igreja católica de 1198 até 1216, é declarada a "miséria da condição humana", como é possível ler em sua obra De contemptu mundi. Esse papa explica que já o neonato é maculado por gravis necessitas et infelix

48 BRUNI, Leonardo. Della milizia. Leonardo Bruni: opere letterarie e politiche. A cura di Paolo Viti. Classici latini. Novara: UTET, 2013. p. 562-563.

49 BRUNI, Leonardo. Introduzione alla dottrina morale. Leonardo Bruni: opere letterarie e politiche. A cura di Paolo Viti. Classici latini. Novara: UTET, 2013. p. 219. 
conditio, já que é pecador mesmo antes de pecar, e presa do erro mesmo antes de errar, o que se constata já na concepção, pois o coito não pode ser realizado sem o prurido da carne, sem a ativação da libido ou sem o vício da luxúria, de modo que a alma assim infusa contrai de origem o pecado, a culpa e a iniquidade. As aflições da vida são compartilhadas por todos os homens, seja patrão, seja servo; seja jovem, seja velho; seja casado, seja celibatário; cada qual percebendo em modo diverso o sofrimento de tal experiência da existência humana.

Os humanistas propõem uma leitura diversa de tal ideia da vida como tristeza e exasperação, iniciam uma tradição europeia que se distancia da ideia ascética e medieval propalada pela Igreja de Inocência. Os humanistas reabilitam assim o homem natural e, ao fazê-lo, redimensionam o sentido da vida humana em sociedade, gerando assim uma nova leitura do Estado, do direito, da economia, da soberania.

Assim, por meio desse estudo, colocou-se luz aos fundamentos históricos e ideológicos do humanismo italiano para demonstrar suas contribuições à teoria do Estado. Foram assim consideradas as forças intelectuais do humanismo que reabilitaram o ser humano como centro da vida e, ao fazê-lo, debelaram uma nova proposta para a vida pública e o governo, com profundos ideais de valorização do ser humano que levou a uma grande profusão de criatividade, arte e civilidade, deduzindo a possibilidade da humanidade natural reencontrar novamente a si mesma.

\section{REFERÊNCIAS}

AQUINO, Tomás de. Commento alla metafisica di Aristotele. 1 v. Bologna: PDUL, 2004.

AQUINO, Tomás de. Do reino ou do governo dos príncipes ao rei de Chipre. In: Escritos políticos de Santo Tomás de Aquino. Tradução de Francisco Benjamin de Souza Neto. Petrópolis: Vozes, 1995.

AQUINO, Tomás de. Suma contra os gentios. 1 v. Tradução: D. Odilão Moura. Porto Alegre: Sulina, 1990.

AQUINO, Santo Tomás de. Suma de teología. Parte I. 4. ed. Madrid: Biblioteca de autores 
cristianos. 2001. Parte I, Cuestión 96, art. 4. p. 853.

ARISTÓTELES. Metafísica. São Paulo: Abril Cultural, 1984.

ARISTÓTELES. Política. 5. ed. São Paulo: Martin Claret, 2001.

AVONDO, Edoardo Ruffini. Il Defensor pacis di Marsilio da Padova. In: Rivista storica italiana. Messina: Giuseppe Principato, 1924. p. 126.

BRUNI, Leonardo. Della milizia. Leonardo Bruni: opere letterarie e politiche. A cura di Paolo Viti. Classici latini. Novara: UTET, 2013.

BRUNI, Leonardo. Difesa contro i riprensori del popolo di Firenze nella impresa di Lucca. Leonardo Bruni: opere letterarie e politiche. A cura di Paolo Viti. Classici latini. Novara: UTET, 2013.

BRUNI, Leonardo. Elogio della città di Firenze. Leonardo Bruni: opere letterarie e politiche. A cura di Paolo Viti. Classici latini. Novara: UTET, 2013.

BRUNI, Leonardo. Introduzione alla dottrina morale. Leonardo Bruni: opere letterarie e politiche. A cura di Paolo Viti. Classici latini. Novara: UTET, 2013.

DANTE, Alighieri. Convivio. In: DANTE Alighieri: tutte le opere. 8. ed. Roma: Grandi Tascabili Economici, 2013.

DE ROOVER, Raymond. Il banco Medici: dalle origini al declino. Firenze: La Nuova Italia Editrice, 1970.

GARIN, Eugenio. L'umanesimo italiano: filosofia e vita civile nel Rinascimento. Roma: Laterza, 1994.

GILSON, Étienne. Études de philosophie médiévale. Strasbourg: Faculté des Lettres, 1921.

GILSON, Étienne. La philosophie au moyen age. Paris: Payot, 1922.

JAEGER, Werner. Umanesimo e teologia. Milano: Corsa dei Servi, 1958.

JOURDAIN, Amable Louis Marie Michel Bréchillet; JOURDAIN, Charles. Recherches critiques sur l'age et l'origine des traductions latines d'Aristote et sur des commentaires grecs ou arabes employés par les docteurs scolastiques. Paris: Joubert, 1819.

LABANCA, Baldassare. Marsilio da Padova: riformatore politico e religioso del secolo XIV. Padova: Fratelli Salmin, 1882. p. 126. 
MARSILIO DA PADOVA. Il difensore minore. Napoli: Guida, 1975.

MARÍSILIO DE PÁDUA. O defensor da paz. Petrópolis: Vozes, 1997.

NUCCIO, Oscar. Diritto naturale e razionalità economica: studi sulle origini medievali dello "spirito capitalistico". Roma: Edizioni dell'Ateneo, 1989.

RAMOS, Alejandro. La ciudad de Dios en Santo Tomás de Aquino. Mar del Plata, Universidad FASTA, 2008.

ULLMANN, Walter. Radici del Rinascimento. Roma: Laterza, 1980. 